Gut, 1978, 19, 669-671

\title{
Tube introducer and modified Celestin tube for use in palliative intubation of oesophagogastric neoplasms at fibreoptic endoscopy
}

\author{
M. ATKINSON, R. FERGUSON, AND G. C. PARKER
}

From the General Hospital, Nottingham

SUMMARY A new method for palliative intubation of inoperable neoplasms at or near the cardia is described. A guidewire is passed through the stricture, which is dilated using Eder Puestow metal olive dilators. The tube to be inserted is mounted on an introducer, which grips its distal end from inside, and is slid into position along the wire under radiological control. Twenty-five patients have been intubated with one death directly resulting from the procedure. The method provides a simple and relatively safe means of relieving dysphagia and improving nutrition.

Palliative intubation to relieve dysphagia and improve nutrition in patients with neoplastic strictures of the oesophagus or cardia can be done using fibreoptic endoscopy, thus avoiding laparotomy with its attendant high mortality (Atkinson and Ferguson, 1977). To facilitate endoscopic intubation or subsequent removal of tubes a new introducer has been devised and to obviate the problem of proximal tube displacement a modified Celestin tube has been constructed. This paper describes the use of the introducer in a consecutive series of 25 patients.

\section{Methods}

INTRODUCER (Fig. 1)

The principle used is to grip the Celestin tube from inside by means of an expanding cup which wedges the cup firmly in the tube lumen. The instrument consists of an inner flexible stainless steel spiral tube upon the distal end of which is mounted the expand-

Received for publication 16 January 1978 ing Delrin plastic cup behind a tapered spiral spring leader. Over this is slid a second spiral tube, the end of which expands into an olive. When pushed home tightly this olive enters and expands the cup. A bayonet type lock on the handle enables it to be fixed in this position. Thus the oesophagogastric tube is held firmly from within until the introducer is unlocked when the olive slides back out of the cup and the tube is released (Fig. 2). The whole assembly is sufficiently rigid to transmit the forces involved in tube insertion and is easily dismantled for purposes of cleaning and sterilisation.

To prevent proximal displacement of the tube a distal shoulder is provided by sliding the amputated funnel of a second tube over the distal end of the Celestin tube and suturing it in this position. Three longitudinal incisions in the shoulder permit it to pass through the stricture during tube insertion.

\section{PROCEDURE}

Histological confirmation of the diagnosis is obtained at a preliminary endoscopy. Subsequently, with the

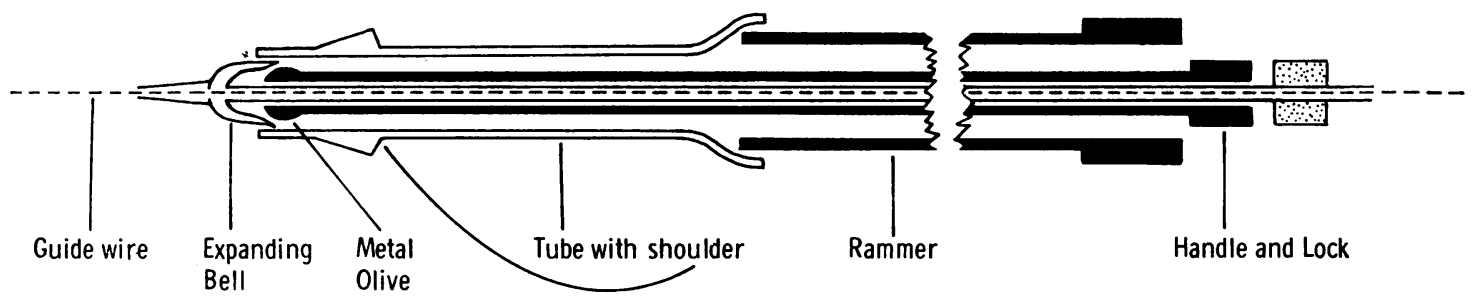

Fig. 1 Diagram of tube mounted on the introducer and guidewire. 


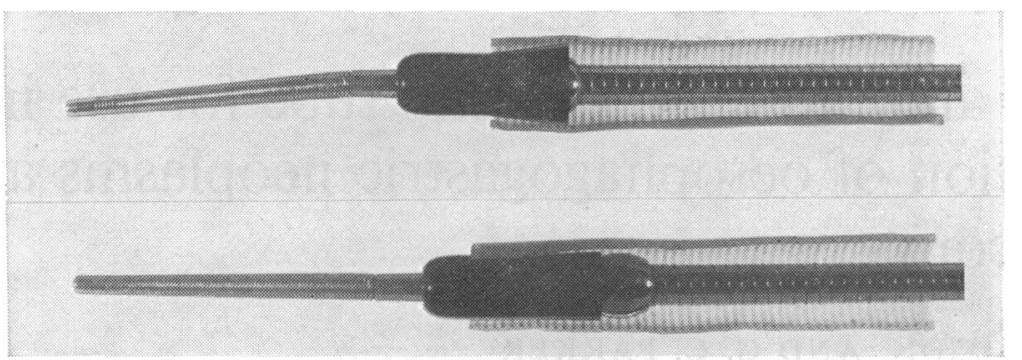

Fig. 2 In the lower picture the Celestin tube, here bisected longitudinally, has been passed over the introducer with the cup unexpanded. In the upper picture the metal olive has been advanced into the cup causing it to expand and grip the tube. patient under general anaesthesia, using a fibreoptic endoscope a stainless steel Eder Puestow guidewire is passed under direct vision into the malignant stricture until radiological screening verifies that the tip of the guidewire lies in the body of the stomach. The endoscope is removed and the stricture dilated up to a 45 French gauge olive using the Eder Puestow metal olive dilators slid along the wire. The guidewire is removed, the endoscope being reintroduced and passed through the stricture to assess its length. The guidewire is reintroduced under direct vision into the stomach. A Celestin tube, cut to appropriate length and with a shoulder attached near its distal end, is mounted on the introducer. A rammer consisting of a large bore plastic coated metal spiral is then fitted over the introducer behind the tube so that its distal end engages in the funnelled proximal end of the tube. Under radiological control the whole assembly is prssed along the guidewire until the funnelled proxin.al end of the tube impacts in the proximal part of the stricture. The introducer is released and it and the wire withdrawn through the tube, which is held in place by the rammer. Finally, the rammer is withdrawn leaving the tube in position.

After intubation the patient is instructed to masticate food carefully and to wash it down with frequent drinks.

\section{PATIENTS}

Each of the 25 patients in whom intubation was attempted had a carcinoma (seven squamous and 18 adenocarcinomata) at or near the cardia resulting in either complete dysphagia necessitating an intravenous infusion or difficulty in taking anything but liquids. After consultation with a surgical colleague all were considered unsuitable for operation because of gross debility or distant metastases. No patient was rejected as being unfit for palliative intubation.

\section{Results}

In one patient intubation was not possible because the Eder Puestow guidewire could not be passed through the malignant stricture. Except for three patients who died in the week after intubation, all left hospital, usually on the third day, swallowing sufficiently well to permit management at home. The average survival time was three months, six have survived for more than six months, and two for more than one year. In five patients with squamous carcinoma, radiotherapy was given with the tube in position.

\section{TUBE FUNCTION}

Early on in the series displacement of the tube proximally occurred in three patients at between one and three days after initial insertion and none of these tubes had been fitted with a distal shoulder. In each the tube was removed using the method for introduction in reverse, and a shouldered tube inserted. In view of these displacements, the later patients in the series had a shouldered tube inserted as a routine procedure and, as yet, no tube fitted with a distal shoulder has displaced proximally. Distal displacement has not been encountered. Tube blockage has not occurred in this series of patients.

\section{MORTALITY AND MORBIDITY}

Perforation of the growth occurred in two patients during intubation. In each the tube was nevertheless inserted and treatment with antibiotics and intravenous fluids started. One patient survived and after seven days oral feeding was established, but the other died of mediastinitis. One patient died of a pulmonary embolus five days after successful intubation and another of respiratory disease after a week.

Symptoms of gastro-oesophageal reflux after intubation were always mild and easily controlled by antacids and sleeping with the bed head raised.

\section{Discussion}

Palliative intubation to permit swallowing in patients with inoperable oesophageal neoplasms was popularised by Souttar (1924) and since then a variety of tubes have been introduced through the rigid 
oesophagoscope (O'Connor et al., 1963; Didcott, 1973; Lewis et al., 1973).

The advent of fibreoptic endoscopes provided a safer means of oesophagoscopy and the better closeup view that is obtained enables more accurate placement of devices through the grossly narrowed lumen of malignant growths. Fibreoptic endoscopy has previously been used to permit dilatation of malignant strictures of the oesophagus or cardia by the Eder Puestow method preparatory to intubation by sliding the tube over a mercury-filled rubber bougie (Boyce, 1973), over the endoscope itself (Tytgat et al., 1976), or over the Puestow wire behind the olive of the Eder Puestow dilator (Atkinson and Ferguson, 1977). The procedural mortality for these methods is well below that of $23 \%-31 \%$ which accompanies intubation using laparotomy and pull through (Ammann and Collis, 1971; Johnson et al., 1976). The introducer used in this study has been designed to minimise trauma to the growth from the projecting leading edge of the tube. The assembly presents a tapered leading end and, by gripping the tube, prevents this riding up during insertion. This mechanism has the added advantage of permitting easy removal of the tube by simply reversing the procedure.

We have found that perforation may occur during the insertion of the guidewire through a growth tightly occluding the oesophageal lumen. If this does happen wherever possible the procedure should be completed, as with intravenous fluids and antibiotics the patient may recover and leave hospital swallowing well.

Tubes inserted by endoscopic means cannot be sutured in position and proximal displacement has been reported (Atkinson and Ferguson, 1977). This problem has been largely overcome by modification of the tube to add a distal shoulder. Tube blockage is largely preventable by ensuring that the patient chews food carefully and that endentulous patients keep to a soft diet.

The Nottingham tube introducer is marketed by Key Med, Specialised Services to Medicine and Industry, Key Med House, Stock Road, Southend-onSea SS2 5QH.

\section{References}

Ammann, J. F., and Collis, J. L. (1971). Palliative intubation of the esophagus. Journal of Thoracic and Cardiovascular Surgery, 61, 863-869.

Atkinson, M., and Ferguson, R. (1977). Fibreoptic endoscopic palliative intubation of inoperable oesophagogastric neoplasms. British Medical Journal, 1, 266-267.

Boyce, H. W., Jr, (1973). Non-surgical measures to relieve distress of later oeso phageal carcinoma. Geriatrics, 28, 97102.

Didcott, D. C. (1973). Oesophageal strictures. Annals of the Royal College of Surgeons of England, 53, 112-126.

Johnson, I. R., Balfour, T. W., and Bourke, J. B. (1976). Intubation of malignant gastro-oesophageal strictures. Journal of the Royal College of Surgeons of Edinburgh, 21, 225-228.

Lewis, R. J., Kunderman, P. J., Sisler, G. E., and Mackenzie, J. W. (1973). Peroral esophageal intubation for obstructive carcinoma of the esophagus. Annals of Thoracic Surgery, 16, 148-157.

O'Connor, T., Watson, R., Lepley, D., Jr., and Weisel, W. (1963). Esophageal prosthesis for palliative intubation. Archives of Surgery, 87, 275-278.

Souttar, H. S. (1924). A method of intubating the oesophagus for malignant stricture. British Medical Journal, 1, 782-783.

Tytgat, G. N., den Hartog-Jager, F. C. A., and Haverkamp, H. J. (1976). Positioning of a plastic prosthesis under fibre-endoscopic control in the palliative treatment of cardio-esophageal cancer. Endoscopy, 8, 180-185. 